EGU21-15254, updated on 01 Feb 2022

https://doi.org/10.5194/egusphere-egu21-15254

EGU General Assembly 2021

(c) Author(s) 2022. This work is distributed under

the Creative Commons Attribution 4.0 License.

\title{
First regional SMOS Sea Surface Salinity products over the Baltic Sea: quality assessment and oceanographic added-value
}

\author{
Veronica Gonzalez Gambau ${ }^{1}$, Estrella Olmedo ${ }^{1}$, Cristina Gonzalez Haro ${ }^{1}$, Antonio Turiel, Aina \\ Garcia ${ }^{1}$, Carolina Gabarro' ${ }^{1}$ Justino Martinez ${ }^{1}$, Pekka Alenius ${ }^{2}$, Laura Tuomi ${ }^{2}$, Petra Roiha ${ }^{2}$, Manuel \\ Arias $^{3}$, Rafael Catany ${ }^{3}$, Diego Fernandez ${ }^{4}$, and Roberto Sabia ${ }^{4}$ \\ ${ }^{1}$ Instituto de Ciencias del Mar, CSIC, Barcelona Expert Center, Barcelona, Spain (vgonzalez@icm.csic.es) \\ ${ }^{2}$ Finnish Meteorological Institute (FMI), Finland \\ ${ }^{3}$ ARGANS Ltd, Davy Road, Plymouth Science Park, Derriford, Plymouth, PL6 8BX \\ ${ }^{4}$ European Space Agency, ESA-ESRIN. Largo Galileo Galilei 1 Casella Postale 6400044 Frascati, Italy
}

The Baltic Sea is a strongly stratified semi-enclosed sea with a large freshwater supply from rivers, net precipitation and water exchange and high-saline water from the North Sea through the Kattegat Strait. In the Danish Straits the water exchange is hampered by bathymetric constraints, such as narrow and shallow sills, and by hydrodynamic restrictions, such as fronts and mixing. The shallow depth of the Baltic Sea (i.e. $54 \mathrm{~m}$ in average) yields to highly variable ocean dynamics controlled mainly by local atmospheric forcing. The water exchange between the Baltic Sea and the North Atlantic Ocean is restricted by the narrows and sills of the Danish Straits (i.e. via Kattergat Strait at the East of the Baltic Sea) and by different river outflows distributed across the Baltic Sea. The bottom water in the deep sub-basins is ventilated mainly by large perturbations, socalled major Baltic saltwater inflows. The occurrence of these events needs still further investigation. The description of the complex oceanographic conditions within the Baltic Sea in current model simulations could also be developed. Furthermore, model simulations of the Baltic Sea are constrained to the initialization of the model (i.e. parametrization of the initial surface atmospheric and ocean conditions).

For this, the Earth Observation salinity measurements have a great potential to help in the understanding of the dynamics in the basin and to improve the regional models there. However, the Baltic Sea is one of the most challenging regions for the sea surface salinity (SSS) retrieval from satellite measurements. The available EO-based SSS products are quite limited over this region both in terms of spatio-temporal coverage and quality. This is mainly due to several technical limitations that strongly affect the satellite brightness temperatures (TB) measurements, particularly over semi-enclosed seas, such as the high contamination by Radio-Frequency Interferences (RFI) and the contamination close to land and ice edges. Besides, the sensitivity of TB to SSS changes is very low in cold waters and much larger errors are expected compared to temperate oceans.

As a main result of the ESA Baltic+ Salinity Dynamics project (), a new regional SSS product derived 
from the measurements provided by the European Soil Moisture and Ocean Salinity (SMOS) mission has been developed. In this work, first, we describe briefly the enhanced algorithms used in the generation of SMOS SSS fields. Second, we show a complete quality assessment by comparing the satellite and the in situ salinity measurements. For this, we use in situ measurements provided by SeaDataNet and Helcom and Ferry box lines. Finally, we compare the satellite salinity measurements with the salinity fields provided by a model. We focus our analysis in two aspects: i) the description of the freswater fluxes coming from continental discharge and sea-ice melting; and ii) the capability of describing the dynamics of the saltier Atlantic water that enters into the basin through the Kattegat strait. 